\title{
The unusual wet summer (July) of 2014 in Southern Europe
}

2

3

\section{Satyaban B. Ratna, J. V. Ratnam, Swadhin K. Behera,}

Application Laboratory, Japan Agency for Marine-Earth Science and Technology, Yokohama 236-0001, Japan

Annalisa Cherchi

Centro Euro-Mediterraneo sui Cambiamenti Climatici and Istituto Nazionale di Geofisica e Vulcanologia, Bologna, Italy

Wanqiu Wang

${ }^{3}$ Climate Prediction Center, NOAA/NWS/NCEP, College Park, Maryland, USA

Toshio Yamagata

Application Laboratory, Japan Agency for Marine-Earth Science and Technology, Yokohama 236-0001, Japan

2

13

14

5

6

18

.
\section{0}


32 Southern Europe (Italy and the surrounding countries) experienced an unusual wet summer in 2014. The monthly 33 rainfall in July 2014 was $84 \%$ above (more than three standard deviation) normal with respect to the 1982-2013 July 34 climatology. The heavy rainfall damaged agriculture, and affected tourism and overall economy of the region. In this study, we tried to understand the physical mechanisms responsible for such abnormal weather by using model and observed datasets. The anomalously high precipitation over Italy is found to be associated with the positive sea

37 surface temperature (SST) and convective anomalies in the tropical Pacific through the atmospheric teleconnection.

38 Rossby wave activity flux at upper levels shows an anomalous tropospheric quasi-stationary Rossby wave from the

39 Pacific with an anomalous cyclonic phase over southern Europe. This anomalous cyclonic circulation is barotropic 40 in nature and seen extending to lower atmospheric levels, weakening the seasonal high and causing heavy 41 precipitation over the Southern Europe. The hypothesis is verified using the National Centers for Environmental 42 Prediction (NCEP) coupled forecast system model (CFSv2) seasonal forecasts. It is found that two-month lead 43 forecast of CFSv2 was able to capture the wet summer event of 2014 over Southern Europe. The teleconnection 44 pattern from Pacific to Southern Europe was also forecasted realistically by the CFSv2 system.

46 Key words: Wet summer; Southern Europe; Italy; Pacific Ocean; Sea surface temperature; teleconnection 


\section{Introduction}

Southern Europe (Italy and neighboring countries) experienced an unusually wet and cold summer (JuneJuly-August) during 2014. Much of these regions were hit by severe storms, flooding and unusually chilly weather. This unprecedented weather during the summer affected the socioeconomic conditions of these regions in terms of agriculture and tourism. The unusual wet and cold conditions delayed the grape ripening and harvest had been hindered that caused the Italian wine production fell by 15 percent as per the report of International Organization of Vine and Wine (OIV, 2014). The cool and wet summer contributed a drop of $34 \%$ in the Italian olive oil production according to International Olive Council (OIC, 2015). As per the report from the Food and Agriculture Organization of the United Nations, heavy summer rainfall drenched some of France's key wheat-growing areas during this summer (FAO, 2014). Entire tomato and lattice fields also have been destroyed by persistent torrential rains. The summer rain washed out family holidays and resulted in the loss of millions of euros in the tourism industry as reported in several news media (Pasquaré and Venturini, 2016).

Southern Europe is the part of Mediterranean region that lies in a transition zone between the arid climate of North Africa and the wet climate of central Europe. The transition zone climate is influenced by interactions between mid-latitude and tropical processes (Raicich et al. 2003; Giorgi and Lionello, 2008). This region experiences a hot, dry, sunny summer and a rainy winter season. In the boreal summer, the region is characterized by descending motion (Raicich et al. 2003) and a minimum in seasonal rainfall (Mariotti et al. 2002). The interannual variability of the circulation over the Atlantic-European sectors is affected by several teleconnections such as the North Atlantic Oscillation (Hurrell, 1995; Kutiel et al. 1996; Brunetti et al. 2002; Zveryaev, 2004; Folland et al. 2009), El Niño-southern oscillation (Fraedrich and Muller 1992; Dai et al. 1997; Trenberth et al. 1998; Behera et al. 2013) and Asian summer monsoons (Rodwell and Hoskins 1996; Tyrlis et al. 2013; Cherchi et al. 2014). While it is the tropical sea surface temperature (SST) that most directly affects the overlaying large-scale atmospheric circulations (Lau 1985; Lau and Nath 1994; Stern and Miyakoda 1995), atmospheric teleconnections from the tropics to the extratropics may lead to some seasonal forecast skill in the extratropics via SST forcing of the tropical atmosphere (Barnston 1994).

Due to its more northerly location and smaller spatial scale of the North Atlantic oscillation (NAO) during the summer, its influence over the European climate diminishes compared to the winter counterpart (Folland et al. 2009). Also, due to the northward location of NAO during the summer season, the Mediterranean region is not under 
the direct influence of the pressure anomalies associated with it and so its relationship with the Mediterranean rainfall is small (Bladé et al. 2012). During July 2014, even though the NAO was weak with a slightly positive

(http://www.cpc.ncep.noaa.gov/products/precip/CWlink/pna/norm.nao.monthly.b5001.current.ascii.table), southern Europe experienced unusual excess rainfall. Also, the weak Asian monsoon can cause enhanced upward motion over the Mediterranean region through monsoon-desert mechanism (Rodwell and Hoskins, 1996) and the Indian summer monsoon in July 2014 was $10 \%$ below the normal. However, such negative Indian summer monsoon rainfall anomaly had never caused such rainfall extreme over the Southern Europe. So, the persistent rainfall throughout July is likely related to other teleconnections arising from large-scale climate variations or could be related with internal variability. There are known difficulties in the prediction of boreal summer climate in mid-latitudes (Zveryaev, 2004; Johansson et al. 1998; Colman and Davey, 1999; Dirmeyer et al. 2003) and so further detailed analysis of the variability of summer climate is extremely important. The present study describes the exceptional event and it also shows possible link of the event with the forcing from the sea surface temperature in the Pacific and teleconnection patterns of the atmospheric circulation.

\section{Data and Methodology}

In this study, the abnormal high precipitation is verified using the monthly precipitation data from the Global Precipitation Climatology Project version 2 (GPCP; Adler et al. 2003) and NOAA precipitation reconstruction over the land (PREC/L; Chen et al. 2002) datasets. The GPCP data is available from 1979 and the PREC/L data from 1948 and both datasets are available at 2.5 degrees horizontal resolution. The anomaly for these data is generated from the climatology based on the period from 1982 to 2013. Apart from this, we also used monthly TRMM 3B43 data (Huffman et al. 2007) available at 1-degree resolution for the verification of the event. The daily variability of the precipitation during July 2014 is investigated with the aid of the GPCP daily data (Huffman et al. 2001) at 1-degree resolution. The SST anomaly is derived from the National Oceanic and Atmospheric Administration (NOAA) Optimum Interpolation sea surface temperature version 2 (OISSTv2; Reynolds et al. 2002) available at 1 degree resolution. Monthly mean surface temperature, sea level pressure, along with meridional and zonal wind data, and geopotential heights at various levels were taken from the Interim European Centre for Medium-Range Weather Forecasts (ECMWF) Re-Analysis (ERA-Interim; Dee et al. 2011), available at 1-degree spatial resolution. 
In addition to the analysis based on observational data, we also investigate if a coupled general circulation

model is able to represent the teleconnection that caused the excess rainfall over the Southern Europe. Here, we used the operational products from the NCEP climate forecast systems version 2 (CFSv2; Saha et al, 2006). The atmospheric component of CFS is the NCEP Global Forecast System model that has a spectral triangular truncation of 126 waves (T126) in the horizontal (equivalent to nearly a 100-km grid resolution) and a finite differencing in the vertical with 64 sigma-pressure hybrid layers. The oceanic component of CFSv2 is the NOAA Geophysical Fluid Dynamics Laboratory Modular Ocean Model (Griffies et al, 2004) version 4. The details of the model and its operational forecasts are described by Saha et al (2014).

The CFSv2 generates nine-month forecasts as a part of the seasonal prediction system and it is initialized four times per day $(0000,0600,1200$, and 1800 UTC). The CFSv2 forecast integrations cover the first partial month and nine full subsequent months into the future. In this study, we use the lagged ensemble of 40 forecast runs initialized from 21-30 April 2014 with four forecast members from each day. We diagnose forecast monthly mean fields of sea surface temperature, precipitation, and atmospheric data such as geopotential height, zonal and meridional winds at $200 \mathrm{hPa}$ for July 2014, corresponding to a lead time of two months. As per the availability of CFS data, the anomalies are computed with respect to the 1999-2010 hindcast climatology.

The vertical motion and the associated low level convergence and upper level divergence induced by the equatorial sea surface temperature anomaly produce an anomalous vorticity source in the tropics. The upper level component of this vorticity source, denoted the Rossby wave source (RWS) by Sardeshmukh and Hoskins (1988), sets off a train of Rossby waves that comprise teleconnection patterns in the extratropics. As per Qin and Robinson (1993), the RWS is given by

$$
\mathrm{RWS}=-\boldsymbol{V}_{\chi}^{\prime} \cdot \boldsymbol{\nabla}(\bar{\zeta}+f)-(\bar{\zeta}+f) \boldsymbol{\nabla} \cdot \boldsymbol{V}_{\chi}^{\prime}-\zeta^{\prime} \boldsymbol{\nabla} \cdot \overline{\boldsymbol{V}}_{\chi}-\overline{\boldsymbol{V}}_{\chi} \cdot \boldsymbol{\nabla} \zeta^{\prime}
$$

Where $\boldsymbol{V}_{\chi}$ is the rotational wind vector, $\zeta$ the relative vorticity and $f$ the Coriolis parameter. $\left(^{-}\right)$and $\left(^{\prime}\right.$ ) represent the climatological mean and perturbation, respectively. The above equation is the breakdown of the full RWS (Sardeshmukh and Hoskins, 1988$)$ into the tropical $[\mathrm{S} 1+\mathrm{S} 4(\approx \mathrm{S} 1)]$ and extratropical parts $(\mathrm{S} 2+\mathrm{S} 3 \approx \mathrm{S} 2)$, which is instructive for evaluating the different roles played by these components in generating extratropical responses. It is found that S1 is more effective than S2 in exciting extratropical teleconnections (Sardeshmukh and Hoskins, 1988) and so in this study we calculated only S1 term to represent the RWS. 


\section{Results}

\subsection{Precipitation anomaly}

Southern Europe experienced very high precipitation during July of 2014. The precipitation anomaly exceeding more than three standard deviations is seen over northern Italy and eastern France and Switzerland (Fig 1). In addition, anomalous high precipitation is seen over the neighboring regions in Switzerland, France, Germany, Austria, Slovenia, Croatia and western Hungary. The anomalous positive precipitation can be seen in all the datasets analyzed in this study (Figure 1a, b, c) though variations in the magnitude of anomalies are noticed. The northern Europe experienced below normal precipitation during the same period (Fig 1a, b). Due to the limitation of the availability of the TRMM precipitation at latitudes higher that $50^{\circ} \mathrm{N}$, the below normal precipitation over north Europe is not seen in Fig 1c. It is reported that during July 2014 cities like Turin, Milan, Venice, Parma, Lucca in Italy received 3 to 9 times more rainfall compared to the July climatology (Pasquaré and Venturini, 2016). Analyzing the interannual variability of precipitation averaged over an area $3^{0} \mathrm{E}-18^{\circ} \mathrm{E}$ and $41^{\circ} \mathrm{N}-50^{\circ} \mathrm{N}$ (box in Figure 1a, b, c) over the period 1982-2014, it can be seen that Italy and surrounding regions received a record excess of rainfall greater than 3 standard deviation (Fig. 1d) in July 2014, which is $84 \%$ higher compared to the July climatology. This value is the highest in the study period of 33 years. This abnormal rainfall in July 2014 is also highest during the past 114 years (1901-2014) in the Climate Research Unit (CRU; Harris et al. 2014) precipitation dataset (not shown). The area averaged daily precipitation over the study domain shows high precipitation in almost all the days of July 2014 compared to the climatological values (Fig 2a). The region received rainfall greater than $1 \mathrm{~mm} /$ day for about 25 days in July 2014 (Fig $2 \mathrm{~b}$ ) out of which 8-10 days were having high amount (> $10 \mathrm{~mm} /$ day) of rainfall. Climatologically, July is the month receiving the lowest seasonal rainfall in this region compared to the other months of the year but the July 2014 was an abnormal month with anomalously high precipitation.

\subsection{Surface temperature and circulation anomaly}

The surface temperature anomalies during July 2014 show negative values (Fig 3a) over southern Europe and low anomalies of mean sea level pressure (Fig 3b). On the other hand, northern Europe, which experienced below normal precipitation, had large positive temperature anomaly (Fig 3a) with positive anomalies of sea level pressure (Fig 3b). The 850 level geopotential height shows an anomalous low with a cyclonic circulation centered over Italy. This low pressure and associated cyclonic circulation extends to the upper troposphere (200 $\mathrm{hPa}$, Fig 3d), indicating a clear barotropic nature. At the same time over northern Europe, sea level pressure anomalies are 
characterized by a high with associated anticyclonic circulation extending from the surface to upper troposphere. The above normal surface temperature associated with anticyclonic circulation over the Scandinavia region in the northern Europe is caused by blocking in the atmosphere (Tyrlis et al, 2015). The atmospheric blocking plays an important role in the mid-latitude climate variability and can be responsible for anomalous mean and/or extreme climate. Dipole patterns of surface temperature and precipitation over Europe have been related to blocking (Behera et al. 2013; Christensen et al. 2013; Sillmann and Croci-Maspoli, 2009; Masato et al. 2012, 2013) caused by the quasi-stationary waves generated by SST anomalies in the Pacific Ocean (Behera et al. 2013). In the next section, we see if similar processes were responsible for the precipitation anomaly in Europe during July 2014.

\subsection{Teleconnection}

To investigate the role of large scale processes that might have contributed to the anomalous low over southern Europe during July 2014, we analyzed the global sea surface temperature and precipitation. The SST anomalies in July 2014 were warmer than normal north of the equator throughout the Pacific Ocean (contour, Fig 4a). The SST anomalies were warmer than normal during this rather unusual El Niño year, when the warm signal suddenly died after July to revive again in late autumn. A weak negative Indian Ocean Dipole (IOD; Saji et al. 1999) also existed in the Indian Ocean during this time (Fig. 4a). A negative IOD can reduce monsoon rainfall over the Indian sub-continent and this may lead to enhanced upward motion and wet condition over the Mediterranean region through monsoon-desert mechanism (Rodwell and Hoskins, 1996). On the other hand, the enhanced monsoon through a positive IOD can cause descent over the Mediterranean region (Guan and Yamagata, 2003). The tropical and subtropical Pacific also received above normal precipitation (above 2 to 3 standard deviations) during July 2014 (shaded; Fig 4a). The abnormal precipitation is seen extending from west to east in the tropical Pacific and the precipitation over the tropical Pacific Ocean $\left(140^{0} \mathrm{E}-270^{0} \mathrm{E} ; 5^{0} \mathrm{~N}-15^{\circ} \mathrm{N}\right)$ in July 2014 exceeded the July $1982-2013$ climatology by $45 \%$. Even the precipitation over Pacific is very high compared to the other years when the Pacific Ocean was warmer than normal in July (not shown). This unusually strong convective activity and related precipitation can induce climatic signal over remote areas through teleconnections.

The positive SST anomalies in the tropical Pacific (Fig 4a) in July 2014 have caused enhanced convection and created upper level divergence (Fig 4b). This upper level divergence generates anomalous sources for the Rossby waves (Sardeshmukh and Hoskins, 1988) through interaction with the upper level westerlies in the subtropical regions. The anomalous tropical Rossby wave source (RWS) associated with the tropical heating is due 
to the advection of the mean absolute vorticity by the anomalous divergent flow (Qin and Robinson, 1993). The anomalous divergence at $200 \mathrm{hPa}$ during July 2014 (Fig 4b) interacts with the westerlies in the subtropical region (Fig 5a; contours) and generates an anomalous RWS in the region over subtropical eastern Pacific and mid-latitude central-north Pacific (Fig 5a; shaded). To see if the quasi-stationary Rossby wave generated due to the anomalous RWS affected the climate of southern Europe during July 2014, we calculated the wave activity flux (Takaya and Nakamura, 2001). The anomalous wave activity flux originates from a source located in the subtropical eastern Pacific (Fig 5b). It is noted that the surrounding region in the Pacific also received record rainfall during July 2014, exceeding by about $70 \%$ to the $1982-2013$ July climatology. The wave activity from this subtropical eastern Pacific is seen as a major contributor to the anomalous quasi-stationary Rossby wave (vector, Fig 5b) reaching Europe, though another minor source appears in the mid-latitude central-north Pacific, west of the dateline. The anomalous quasi-geostrophic streamfunction also clearly shows a quasi-stationary wave from the eastern Pacific to the Europe (shaded, Fig 5b). The spatial pattern of the generated anomalous Rossby wave train is such that it favors a cyclonic circulation over Italy and its surrounding region (shaded, Fig 5b) reinforcing an anomalous equivalent barotropic low there. We have also verified the wave train by analyzing the meridional wind anomaly (Fig. 5c) which shows wave extending from the Pacific Ocean to Italy. Such mid-latitude circumglobal teleconnections during the Northern 201 Hemisphere summer are discussed in a few previous studies (Ding and Wang, 2005; Lin 2009; Yasui and Watanabe, 2010; Ding et al. 2011). The above analysis shows that the anomalies in the atmospheric convection/precipitation caused upper level divergence, which on interaction with the upper level westerlies generated anomalous quasistationary Rossby waves. The resulted anomalous cyclonic circulation resulted in higher than normal precipitation over Italy in July 2014.

Given the understanding that the diabatic heating over the tropical Pacific is largely responsible for the 207 excess rainfall over southern Europe, we wanted to see if the event was predicted by the CFSv2 system. The 208 ensemble mean CFSv2 precipitation anomaly (Fig 6a) shows positive anomalies over southern Europe and negative anomalies over north and northeast Europe, similar to the observed precipitation anomalies, though weaker in magnitude. The CFS forecasts could capture the SST and convective anomalies over Pacific realistically (Fig. 6b).

211 The anomalous quasi-stationary wave from the Pacific to southern Europe was also captured realistically as seen 212 from the Rossby wave flux anomalies (Fig 6c) and the 200hPa meridional wind anomalies (Fig 6d). 

anomalies over Southern Europe among the members. We compared those members by grouping the members that 215 forecasted wet July 2014 (hereafter ENSwet) against those ensemble members that forecasted dry July 2014 216 (hereafter ENSdry). A total of four members were found in each category. The forecast rainfall over Italy from the ensemble mean of ENSwet and ENSdry are presented in Figure 7a, b. The differences between ENSwet and ENSdry clearly shows positive rainfall anomaly over Italy region (Fig. 7c). The corresponding SST anomaly difference between ENSwet and ENSdry shows positive anomaly over central, west and subtropical Pacific (Fig. 7f). It is seen that ENSwet anomaly predicted excess rainfall over the Pacific Ocean compared to ENSdry (Fig. $7 \mathrm{~g}, \mathrm{~h}$ ) and the difference is more over central Pacific north of the equator. This is the region for the source of Rossby waves 222 discussed in the observed analysis. Next, we plotted the meridional wind anomaly for the ENSwet and ENSdry to check the differences in the wave from Pacific to Italy. It is seen that the simulated wave with ENSwet (Fig. 7j) is clear and close to the observation. These differences in those two sets of ensemble forecasts further demonstrated that the excess rainfall observed in the tropical and subtropical Pacific generated the Rossby wave to cause excess rainfall over Italy. The CFSv2 forecast confirms the mechanism revealed by observational data and demonstrates that the coupled model is capable of predicting the excess rainfall over southern Europe and associated teleconnection from the Pacific.

\section{Summary}

In this study, we tried to understand the mechanism for the record high precipitation observed over southern Europe (Italy and its surrounding region) during July 2014. To determine the processes responsible for the rainfall and the associated cyclonic anomalies over Italy, we analyzed global observed SST, precipitation as well as atmospheric circulation anomalies for this extreme summer. It is seen that the SST anomalies were anomalously positive in the tropical Pacific during July 2014. Positive precipitation anomalies were also seen over the tropical and subtropical Pacific. The corresponding upper level divergence over the subtropical Pacific generated an anomalous Rossby wave source at $200 \mathrm{hPa}$. The Rossby wave activity flux analysis demonstrated the anomalous RWS and the associated Rossby wave extending from the Pacific to southern Europe. The phase of the generated wave was such to favor cyclonic circulation over Italy and the surrounding countries. We have reported this relationship for the first time and we think that it could be an important factor for the extreme rainfalls over southern 
other atmospheric internal variability. As the event described in the paper is unique for what we have found so far, we cannot fully demonstrate the cause-effect relationship and identify it as a clear teleconnections. To fully assess a direct cause-effect mechanism the event should be demonstrated using other observations or simulations, but the lack of similar events in the available data is not sufficient for demonstrating the cause-effect relationship. CFSv2 seasonal forecast. The CFSv2 captured the precipitation anomaly over Europe at the two-month lead time with the positive anomaly over the southern Europe and negative anomaly over north and northeast Europe. The model predicted the warm SST and excess rainfall over the subtropical Pacific similar to the observation. This enhanced precipitation over the Pacific could have generated the Rossby wave through the diabatic heating in the atmosphere, which can be seen from the wave activity flux. The CFSv2 model output is also analyzed by separating the ensembles, which generated positive and negative rainfall anomalies over Italy. It is identified that the ensemble members with wet anomaly over Italy also simulated wet anomalies in the subtropical Pacific compared to the ensemble with dry anomaly over Italy. The ensembles with wet anomalies over Italy compared to dry ensembles also simulated the wave realistically as in the observations.

The present study focuses on the mechanism for the unusual summer precipitation over southern Europe during July 2014 on the possible link with the teleconnection patterns of the atmospheric circulation. Understanding the observational links and relationship with the summer climate system may lead to an improved ability for seasonal predictions of the European climate. More studies are desirable to analyze forecasts from other global model forecast systems to see the fidelity of those models in predicting the observed extreme events.

\section{Acknowledgement:}

262 We are thankful to the two anonymous reviewers whose constructive comments helped improving the manuscript.

263 The authors are also thankful to the ECMWF for making available the ERA-Interim reanalysis datasets used in this research. GPCP precipitation, PREC/L precipitation and NOAA OI SST data provided by the NOAA/OAR/ESRL PSD, Boulder, Colorado, USA, from their Web site at http://www.esrl.noaa.gov/psd/. 
269

270 


\section{References}

272 Adler, R.F. et al, 2003. The Version 2 Global Precipitation Climatology Project (GPCP) monthly precipitation

273 analysis (1979-present). J Hydromet. 4:1147-1167.

274 Barnston, A.G., 1994. Linear statistical short-term climate predictive skill in the Northern Hemisphere, J. Clim. 7, $275 \quad 1513-1564$.

276 Behera, S., Ratnam, J.V., Masumoto, Y., Yamagata, T., 2013. Origin of extreme summers in Europe: the Indo277 Pacific connection. Clim Dyn., 41, 663 - 676.

Bladé. I., Liebmann, B., Fortuny, D., Oldenborgh, G.J., 2012. Observed and simulated impacts of the summer NAO 279 in Europe: implications for projected drying in the Mediterranean region. Clim Dyn. 39, 709-727. Brunetti, M., Maugeri, M., Nanni, T., 2002. Atmospheric circulation and precipitation in Italy for the last 50 years, Int J Clim 22, 1455-1471.

Chen, M., Xie, P., Janowiak, J.E., Arkin, P.A., 2002. Global Land Precipitation: A 50-yr Monthly Analysis Based on Gauge Observations, J. Hydromet. 3, 249-266.

Cherchi, A., Annamalai, H., Masina, S., Navarra, A., 2014. South Asian Summer Monsoon and the Eastern Mediterranean Climate: The Monsoon-Desert Mechanism in CMIP5 Simulations. J. Clim. 27, 6877-6903. Climate Change 2013: The Physical Science Basis. Contribution of Working Group I to the Fifth Assessment Report of the Intergovernmental Panel on Climate Change, Stocker, T.F., D. Qin, G.-K. Plattner, M. Tignor, S.K. Allen, J.

291 Colman, A., Davey, M., 1999. Prediction of summer temperature, rainfall and pressure in Europe from preceding 292 winter North Atlantic ocean temperature, Int J Clim. 19, 513-536.

293 Dai, A., Fung, I.Y., Del Genio, A.D., 1997. Surface observed global land precipitation variations 1900-88, J. Clim. $29410,2943-2962$.

295 Dee, D.P., et al 2011. The ERA-Interim reanalysis: Configuration and performance of the data assimilation system. Quart. J. Roy. Meteor. Soc. 137, 553-597.

297 Ding, Q., Wang, B., 2005. Circumglobal teleconnection in the Northern Hemisphere summer. J Clim. 18, 34832983505. 
Ding, Q., Wang, B., Wallace, J.M., Branstator, G., 2011. Tropical-extratropical teleconnections in Boreal summer: observed interannual variability. J Clim. 24,1878-1896.

Dirmeyer, P.A., Fennessy, M.J., Marx, L., 2003. Low skill in dynamical prediction of boreal summer climate: Grounds for looking beyond sea surface temperature, J. Clim. 16, 995-1002.

FAO (Food and Agriculture Organization of the United Nations) 2014. Monthly news report on grains, MNR Issue 108: $1-12$.

Folland, C.K et al., 2009. The summer North Atlantic Oscillation: past, present, and future. J Clim. 22, 1082-1103.

Fraedrich, K., Muller, K., 1992. Climate anomalies in Europe associated with ENSO extremes, Int. J. Climatol., 12, $25-31$.

Giorgi, F., Lionello, P., 2008. Climate change projections for the Mediterranean region. Glo Plan. Chan. 63, 90104.

Griffies, S. M., Harrison, M. J., Pacanowski, R. C. \& Rosati, A., 2004. Technical guide to MOM4. GFDL Ocean Group Technical Report No. 5, 337 pp. [Available online at www.gfdl.noaa.gov/ fms.]

Guan, Z., Yamagata, T., 2003. The unusual summer of 1994 in East Asia: IOD teleconnections. Geophys. Res. Lett., 30.1544, doi:10.1029/2002GL016831

Harris, I., Jones, P.D., Osborn, T.J., Lister, D.H., 2014. Updated high-resolution grids of monthly climatic observations-the CRU TS3.10 dataset. Int J Clim. 34, 623-642.

Huffman, G.J. et al 2001. Global precipitation at one-degree daily resolution from multisatellite observations. J. Hydromet. 2, 36-50.

Huffman, G.J. et al 2007. The TRMM Multi-satellite Precipitation Analysis: Quasi-global, multi-year, combinedsensor precipitation estimates at fine scale. J. Hydromet. 8, 38-55.

Hurrell, J.W., 1995. Decadal trends in the Northern Atlantic oscillation - regional temperatures and precipitation. Science. 269, 676-679.

Johansson, A., Barnston, A., Saha, S., Van den Dool, H. 1998. On the level and origin of seasonal forecast skill in Europe, J. Atmos. Sci. 55, $103-127$.

Kutie,1 H., Maheras, P., Guika, S., 1996. Circulation and extreme rainfall conditions in the eastern Mediterranean during the last century. Int J Clim. 16, 73-92. 
Lau, N-C, Nath, M.J. 1994. A modeling study of the relative roles of the tropical and extratropical SST anomalies in

327 the variability of the global atmosphere-ocean system, J. Clim. 7, $1184-1207$.

Lau, N-C., 1985. Modeling the Seasonal Dependence of the Atmospheric Response to Observed El Niños in 1962 76. Mon. Wea. Rev. 113, 1970-1996.

Lin, H, 2009. Global extratropical response to diabatic heating variability of the Asian summer monsoon. J Atmos Sci. 66, 2697-2713.

Mariotti, A., Struglia, M,, Zengm N,, Laum K-M,m 2002. The hydrological cycle in the Mediterranean region and implications for the water budget of the Mediterranean Sea. J. Clim. 15, 1674-1690.

Masato, G., Hoskins, B.J., Woollings, T.J., 2012. Wave-breaking characteristics of midlatitude blocking. Quart. J. Roy. Meteor. Soc. 138, 1285-1296.

Masato, G., Hoskins, B.J., Woollings, T.J., 2013. Wave-breaking characteristics of Northern Hemisphere winter blocking: A two-dimensional approach. J. Clim. 26, 4535-4549.

OIC-International Olive Council 2015. Olive oils production data. Available at: http://www.internationaloliveoil.org/documents/viewfile/4246-production2-ang/.

OIV-International Organisation of Vine and Wine 2014. Global economic vitiviniculture data. Press Release. Available at: http://www.oiv.int/oiv/files/EN_Press_Release_OIV_23_October.pdf.

Pasquaré M, F., Venturini, C., 2016. 2014, The "year without a summer" in Italy: news media coverage and implications for the climate change debate. Environ Dev Sustain. doi:10.1007/s10668-016-9805-8

Qin, J., Robinson, W.A., 1993. On the Rossby Wave Source and the Steady Linear Response to Tropical Forcing. J. Atmos. Sci, 50, 1819-1823.

Raicich, F., Pinardi, N., Navarra, A., 2003. Teleconnections between Indian monsoon and Sahel rainfall and the Mediterranean. Int J Clim. 23, 173-186.

Reynolds, R.W., Rayner, N.A., Smith, T.M., Stokes, D.C., Wang, W., 2002. An improved in situ and satellite SST analysis for climate. J. Clim. 15, 1609-1625.

Rodwell, M.J., Hoskins, B.J., 1996. Monsoons and the dynamics of deserts. Quart J Roy Meteor Soc 122: 13851404

Saha, S., \& Coauthors., 2006. The NCEP Climate Forecast System. J. Climate, 19, 3483-3517

Saha, S., \& Coauthors., 2014. The NCEP Climate Forecast System Version 2. J. Climate, 27, 2185-2208 
Saji, H.N., Goswami, B.N., Vinayachandran, P.N., Yamagata, T.A., 1999. Dipole mode in the tropical Indian Ocean. Nature. 401, 360-363.

Sardeshmukh, P.D., Hoskins, B.J., 1988. The Generation of Global Rotational Flow by Steady Idealized Tropical Divergence. J. Atmos. Sci. 45, 1228-1251.

Sillmann, J., Croci-Maspoli, M. 2009. Present and future atmospheric blocking and its impact on European mean and extreme climate. Geophys. Res. Lett., 36, L10702, doi:10.1029/2009GL038259.

Stern, W.F., Miyakoda, K., 1995. Feasibility of seasonal forecasts inferred from multiple GCM simulations. J. Clim. $8,1071-1085$.

Takaya, K., Nakamura, H.A., 2001. Formulation of a Phase-Independent Wave-Activity Flux for Stationary and Migratory Quasigeostrophic Eddies on a Zonally Varying Basic Flow. J. Atmos. Sci. 58, 608-627.

Trenberth, K.E. et al 1998. Progress during TOGA in understanding and modeling global teleconnections associated with tropical sea surface temperatures. J. Geophys. Res. 103, 14291-14324.

Tyrlis, E., Lelieveld, J., Steil, B., 2013. The summer circulation over the Eastern Mediterranean and the Middle East: influence of the South Asian monsoon. Clim Dyn. 40, 1103-1123.

Tyrlis, E., Tymvios, F. S., Giannakopoulos, C., Lelieveld, J., 2015. The role of blocking in the summer 2014 collapse of Etesians over the eastern Mediterranean, J. Geophys. Res. Atmos. 120, 6777-6792.

Yasui, S., Watanabe, M., 2010. Forcing processes of the summertime circumglobal teleconnection pattern in a dry AGCM. J Clim. 23.2093-2114

Zveryaev, I.I., 2004. Seasonality in precipitation variability over Europe. J Geophys Res 109 D05103, DOI 10.1029/2003JD003668 775

\section{6}

\section{7}



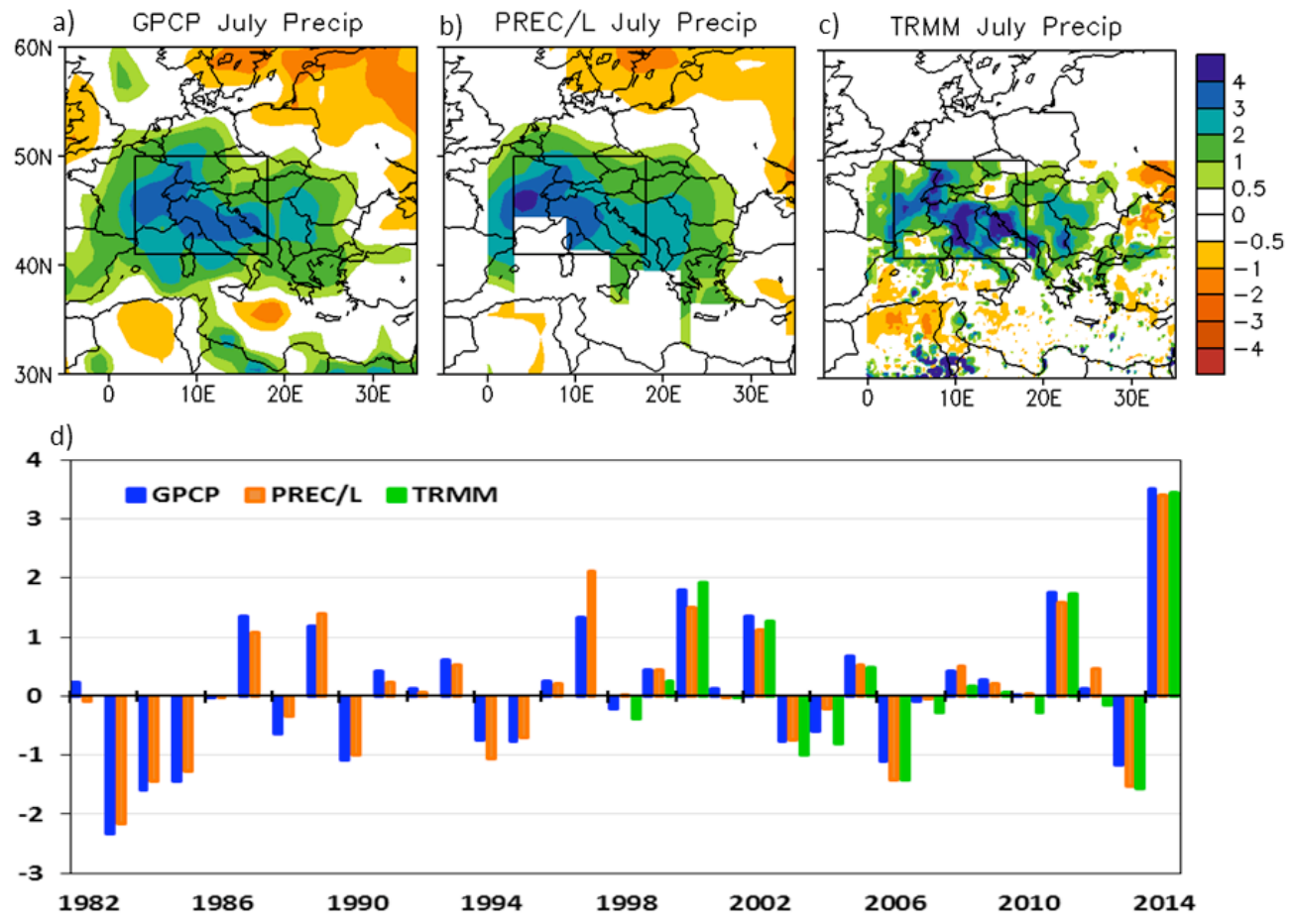

Figure 1. Standardized precipitation anomaly for July 2014 for (a) GPCP (b) PREC/L and (c) TRMM 3B43 data. (d) Interannual variability of standardized precipitation anomaly ( $\mathrm{mm} /$ day) averaged over the area $3^{0} \mathrm{E}-18^{0} \mathrm{E}$ and $41^{\circ} \mathrm{N}-50^{\circ} \mathrm{N}$ (marked as a box in a, b and c) for July month during the period 1982-2014. TRMM data is available over the latitude band $50 \mathrm{~S}-50 \mathrm{~N}$ and for the period 1998-2014. The anomalies are calculated with respect to the July climatology for the period 1982-2013 (1998-2013 for TRMM). 
a)

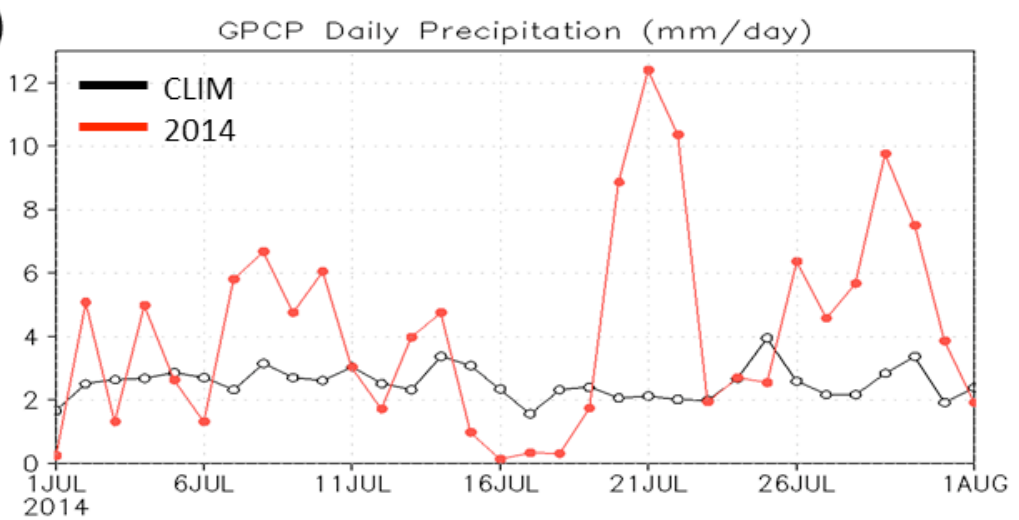

b)

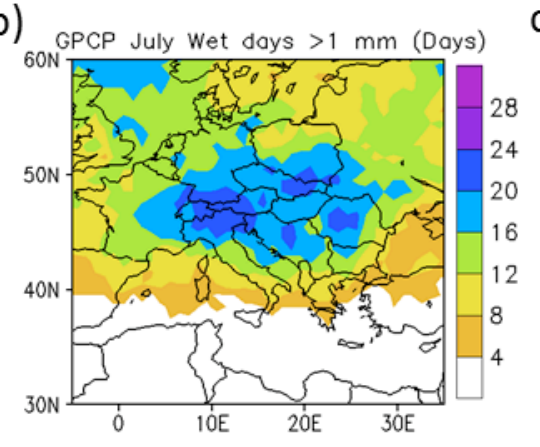

C) GPCP July wet days $>10 \mathrm{~mm}$ (Days)

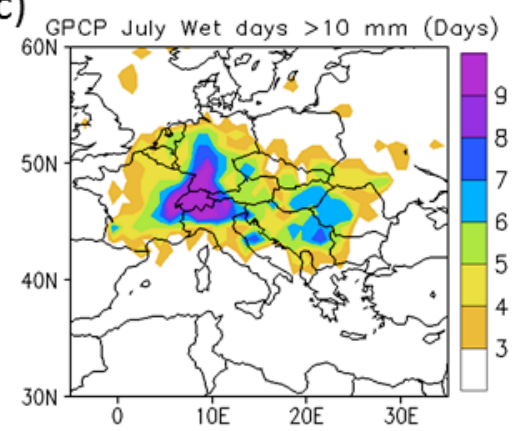

394 Figure 2. (a) Daily precipitation (mm/day) averaged over the area $3^{0} \mathrm{~N}-18^{0} \mathrm{~N}$ and $41^{0} \mathrm{~N}-50^{0} \mathrm{~N}$ for July 2014 (red

395 line) and daily climatology for July (black line). (b) Number of wet days $>1 \mathrm{~mm}$ in July and (c) Number of wet days

$396>10 \mathrm{~mm}$ in July. The climatology for the GPCP daily precipitation is obtained for the period 1997-2014. 


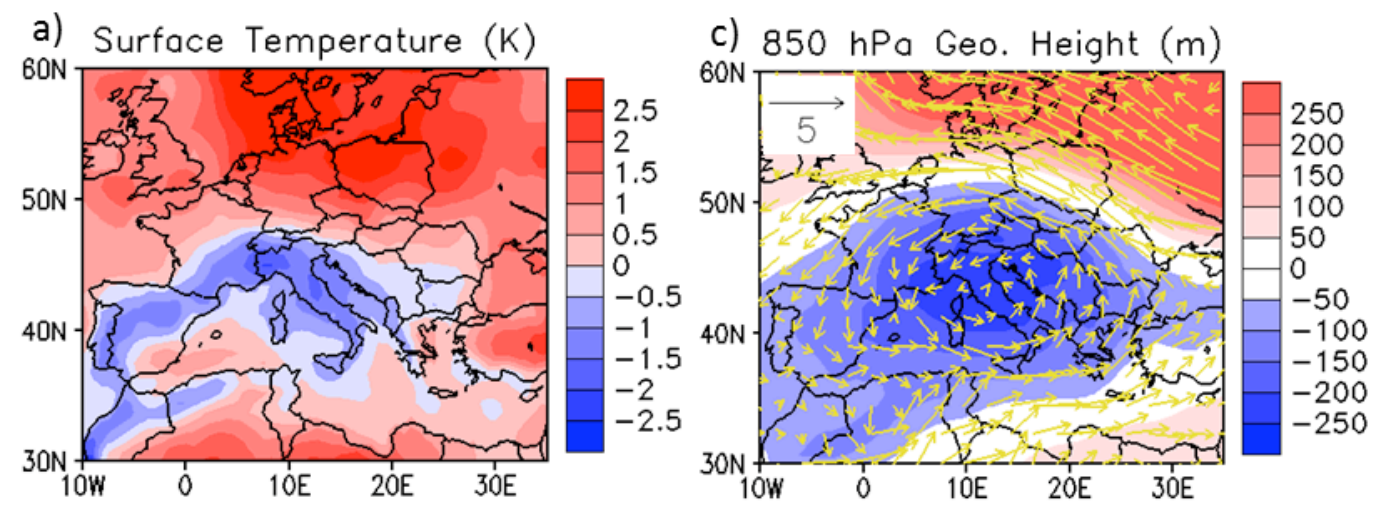

400
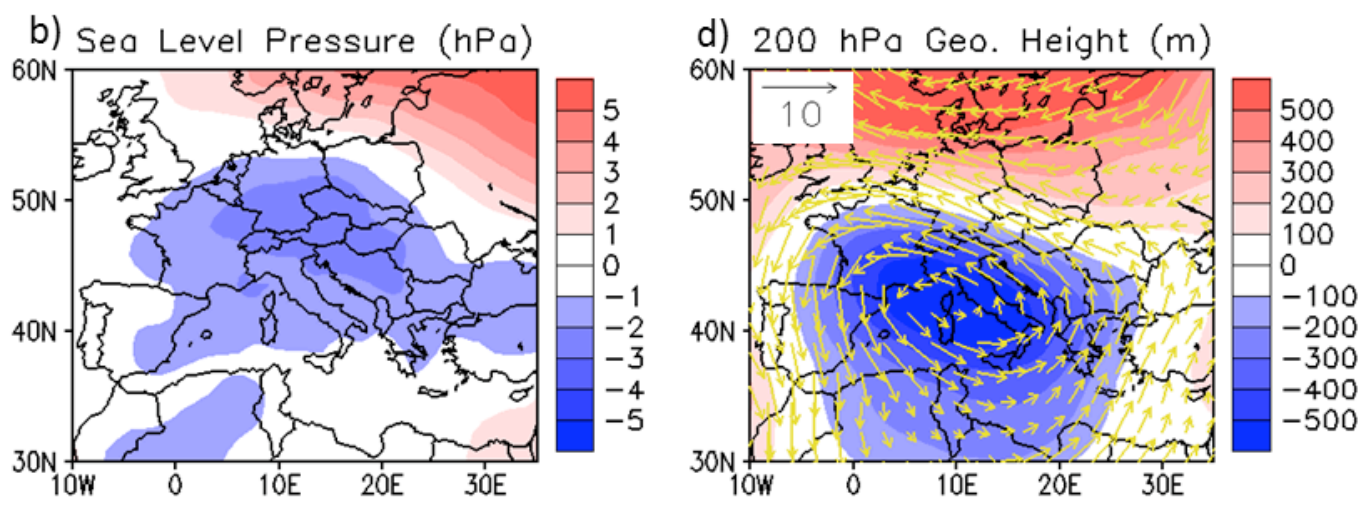

401 Figure 3. (a) Surface temperature anomaly (K) for July 2014. (b) Same as (a) but for the sea level pressure (hPa).

402 (c) Geopotential height (m) and wind vector (m/s) anomaly at $850 \mathrm{hPa}$ level. (d) Same as (c) but for $200 \mathrm{hPa}$ level.

403 All figures are with ERA-Interim data and the anomalies are calculated with respect to the July climatology for the 404 period 1982-2013. 

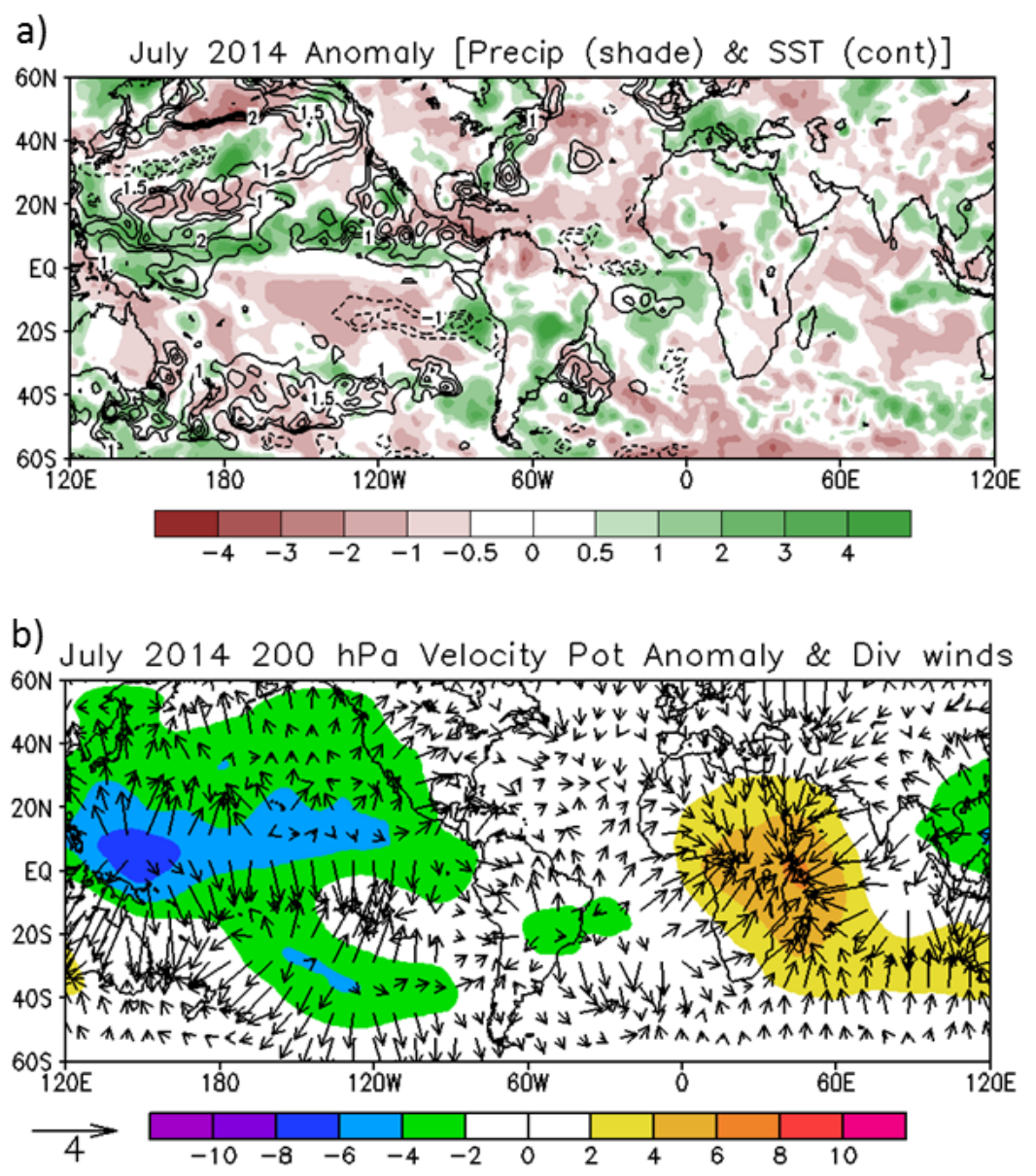

408 Figure 4. (a) Precipitation ( $\mathrm{mm} /$ day, shaded) anomaly and sea surface temperature anomaly (K, contour) for July

4092014 standardized with respect to 1982-2013 climatology. The contours for the SST are drawn at 1, 1.5, 2 and $2.5 \mathrm{~K}$.

410 and (b) Velocity potential $\left(* 10^{6} \mathrm{~m}^{2} \mathrm{~s}^{-1}\right.$, shaded) and divergent component of winds ( $\mathrm{m} \mathrm{s}^{-1}$, vectors) at $200 \mathrm{hPa}$ for 411 July 2014. 

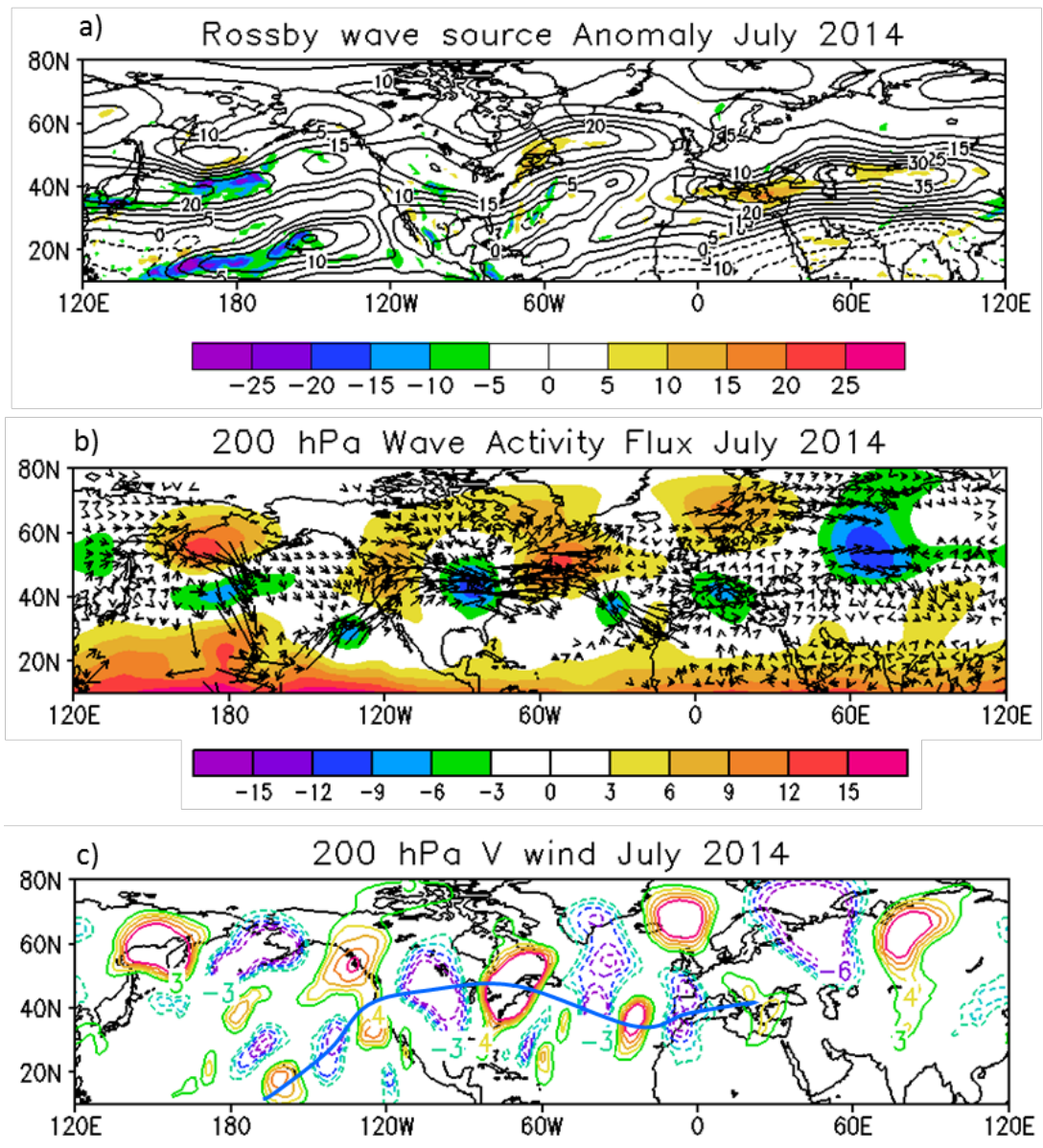

415 Figure 5. (a) Rossby wave source anomaly $\left({ }^{*} 10^{-11} \mathrm{~s}^{-1}\right.$, shaded) and zonal winds (m/s, contours) at $200 \mathrm{hPa}$ for July

416 2014. The negative value of RWS is known as source. (b) Stream function anomaly $\left({ }^{*} 10^{6} \mathrm{~m}^{2} \mathrm{~s}^{-1}\right.$ shaded) and wave

417 activity flux ( $\mathrm{m}^{2} \mathrm{~s}^{-2}$, vector) at $200 \mathrm{hPa}$ level for July 2014. (c) $200 \mathrm{hPa}$ meridional wind anomaly for July 2014. 

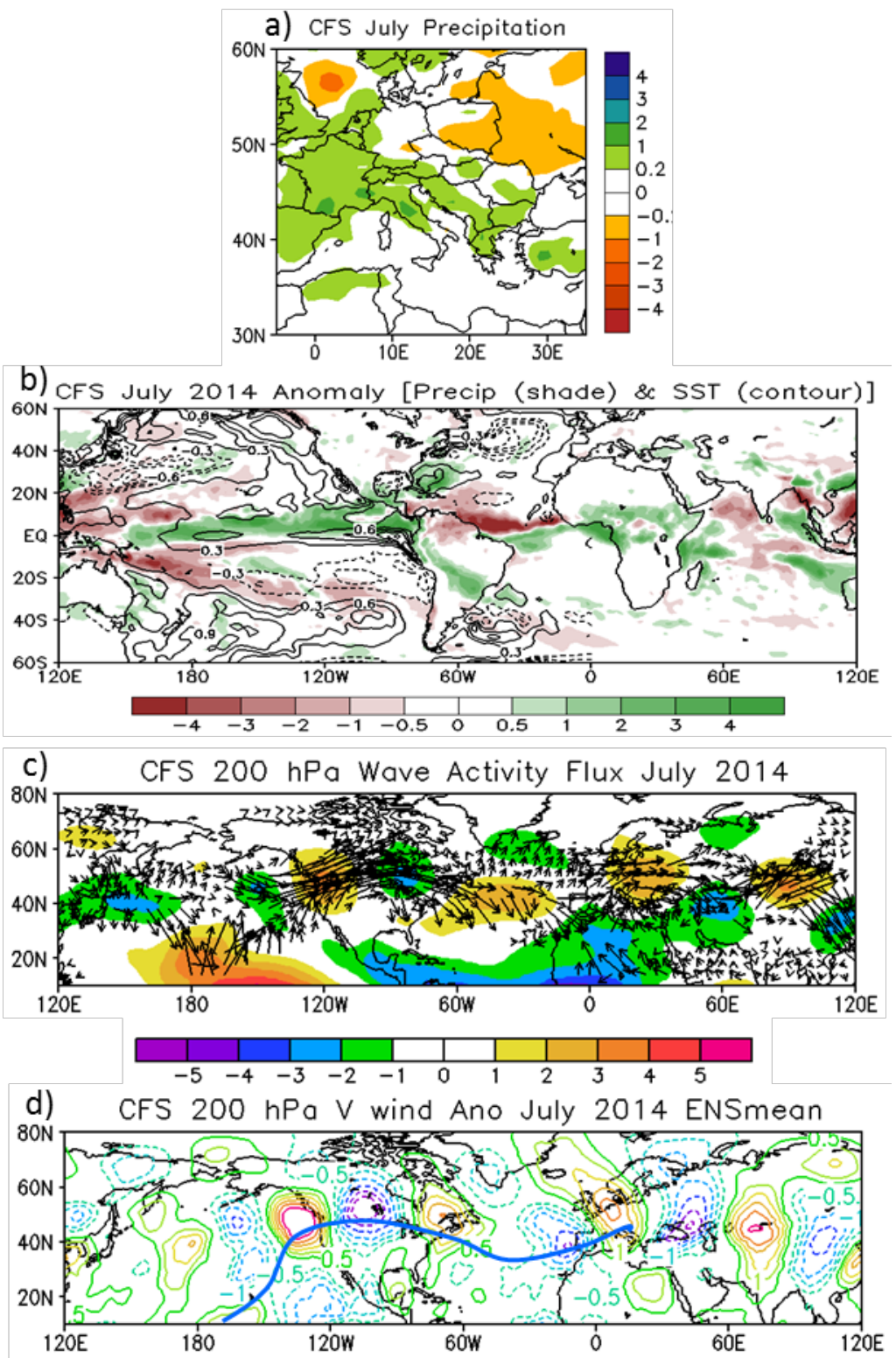

420 Figure 6. (a) CFS forecasted precipitation anomaly (mm/day) over Europe. (b) CFS forecasted Sea surface

421 temperature anomaly ( $\mathrm{K}$, contour) and precipitation ( $\mathrm{mm} /$ day, shaded) anomaly. (c) CFS forecasted stream function 422 anomaly and wave activity flux at $200 \mathrm{hPa}$. (d) CFS forecasted $200 \mathrm{hPa}$ meridional wind (m/s) anomaly for July 4232014. 

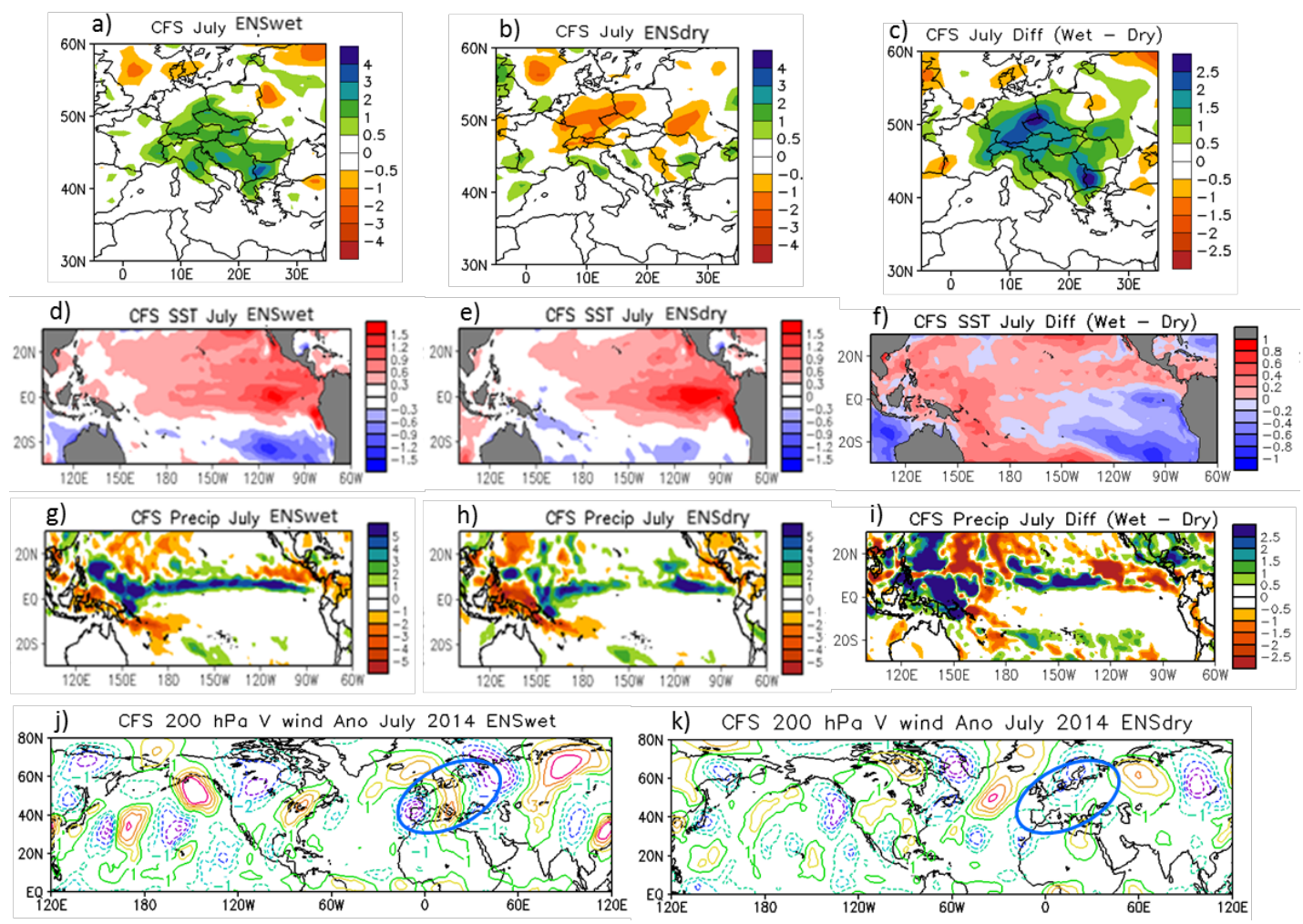

428 Figure 7. Precipitation anomaly over South Europe for those ensembles that generated wet (ENSwet) and dry

429 (ENSdry) anomalies over Italy. (a) ENSwet (b) ENSdry (c) difference between ENSwet and ENSdry. (d, e, f) same 430 as $(a, b, c)$ but for SST anomalies. $(g, h, i)$ same as (a, b, c) but for precipitation anomalies. $(j, k) 200$ hPa meridional 431 wind anomalies for ENSwet and ENSdry. 